\title{
Corrigendum
}

\section{Activation of the cAMP/PKA/DARPP-32 Signaling Pathway is Required for Morphine Psychomotor Stimulation but not for Morphine Reward}

Anders Borgkvist, Alessandro Usiello, Paul Greengard and Gilberto Fisone

Neuropsychopharmacology (2007) 32, 2440; doi:I0.I 038/sj.npp. I 301374; published online 2 May 2007

Correction to: Neuropsychopharmacology (2007) 32, 1995-2003; doi:10.1038/sj.npp.1301321

Following the publication of this article, the authors noted that Dr Fisone was incorrectly affiliated with
CEINGE. He is not affiliated with this institution. Dr Usiello is affiliated to Karolinska Institutet and CEINGE. 